\title{
LA-UR-13-23302
}

Approved for public release; distribution is unlimited.

Title:

Author(s):

Intended for:

Issued:

\section{Highlights of computational work in IC computers}

\author{
Batista, Enrique R. \\ Martin, Richard L. \\ Wen, Xiaodong
}

Report

2013-05-07

\section{- LOSAlamos \\ EST. 1943}

Disclaimer:

Los Alamos National Laboratory, an affirmative action/equal opportunity employer,is operated by the Los Alamos National

Security, LLC for the National NuclearSecurity Administration of the U.S. Department of Energy under contract DE-AC52-06NA25396.

By approving this article, the publisher recognizes that the U.S. Government retains nonexclusive, royalty-free license to

publish or reproduce the published form of this contribution, or to allow others to do so, for U.S. Government purposes.

Los Alamos National Laboratory requests that the publisher identify this article as work performed under the auspices of the

U.S. Departmentof Energy. Los Alamos National Laboratory strongly supports academic freedom and a researcher's right to publish; as an institution, however, the Laboratory does not endorse the viewpoint of a publication or guarantee its technical correctness. 


\section{Accidental degeneracy leads to increased An(5f)-O(2p) hybridization in $\mathrm{PuO}_{2}$ and $\mathrm{AmO}_{2}$}

\section{Enrique R. Batista, Richard L. Martin, and Xiaodong Wen}

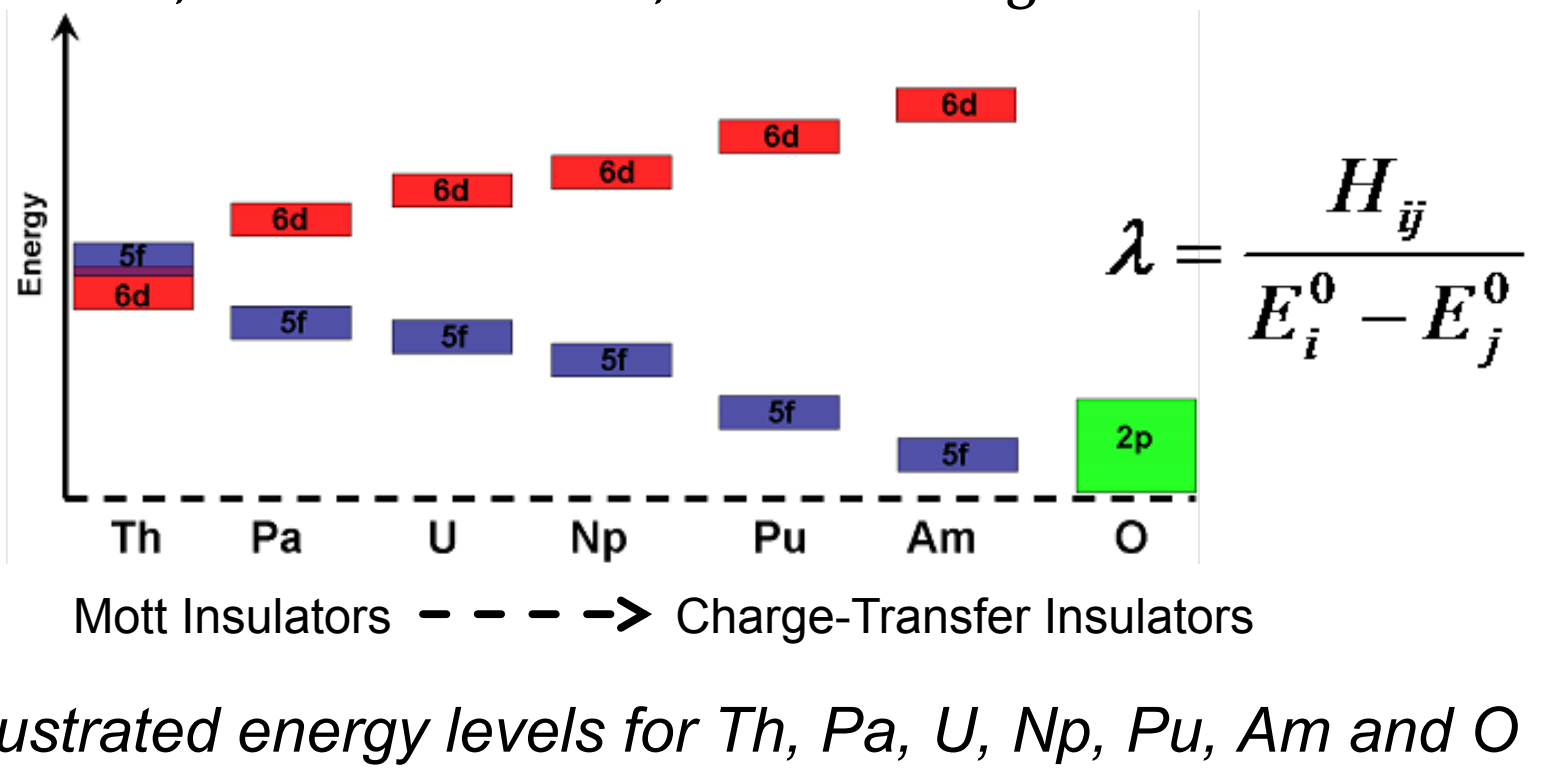

While the actinide contraction suggests that the $5 f$ electrons should become more localized as one moves to the right in the row, our calculations show that the $5 f$ orbital energy decreases steadily across the row, becoming nearly degenerate with the $\mathrm{O} 2 \mathrm{p}$ band beginning with $\mathrm{Pu}$. This proximity in energy drives a significant orbital mixing and increased dispersion in $\mathrm{PuO}_{2}$ and $\mathrm{AmO}_{2}$. This prediction of "unexpected covalency" has recently been confirmed by angle-resolved photoemission experiments. 


\section{Hybrid-DFT prediction of strongly correlated metal, UN}

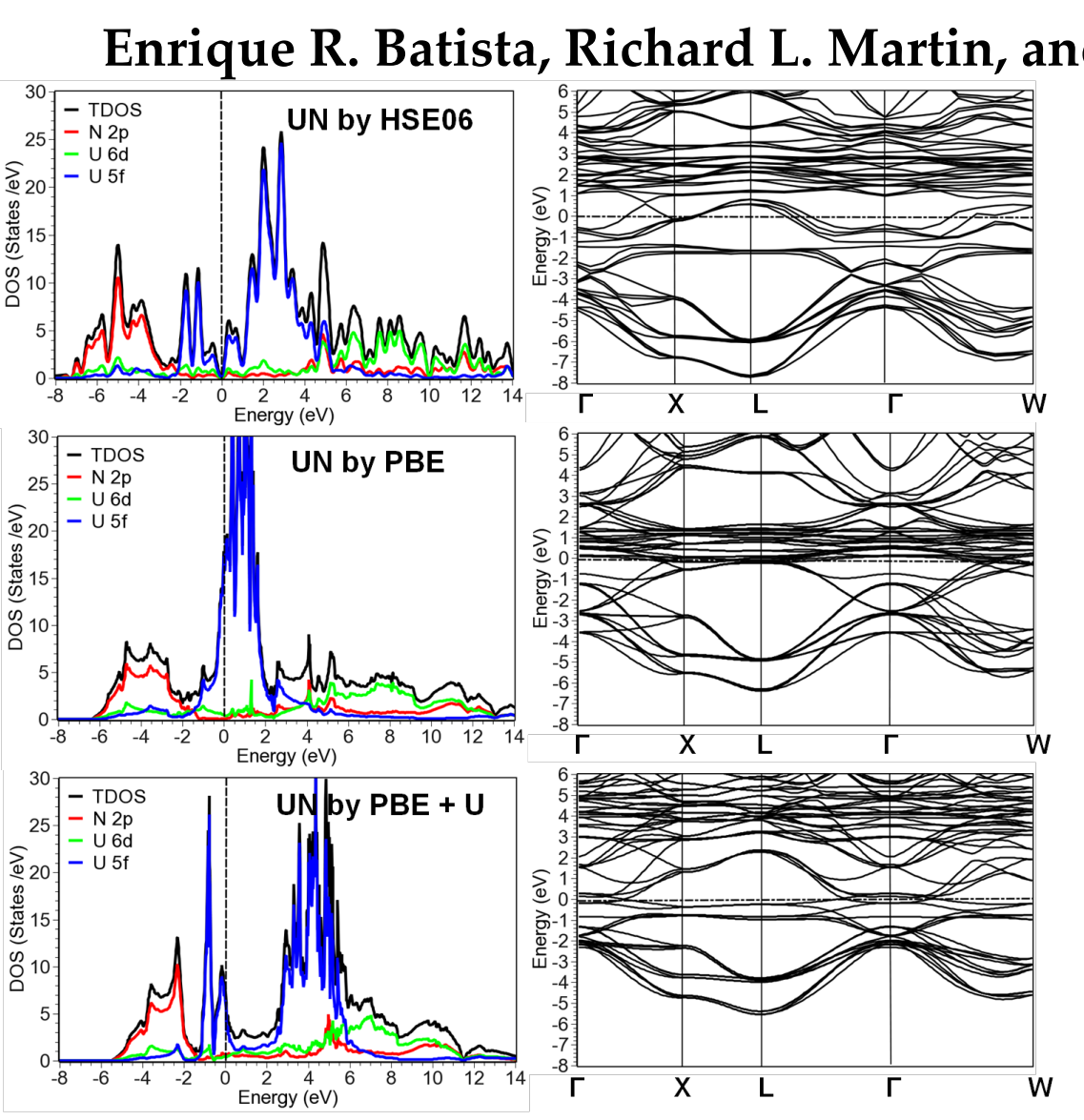

Calculated density of states (DOS) and band structure for AFM $U N$ by $P B E, P B E+U$ and HSE.

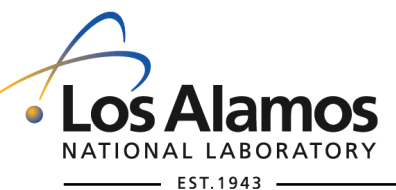

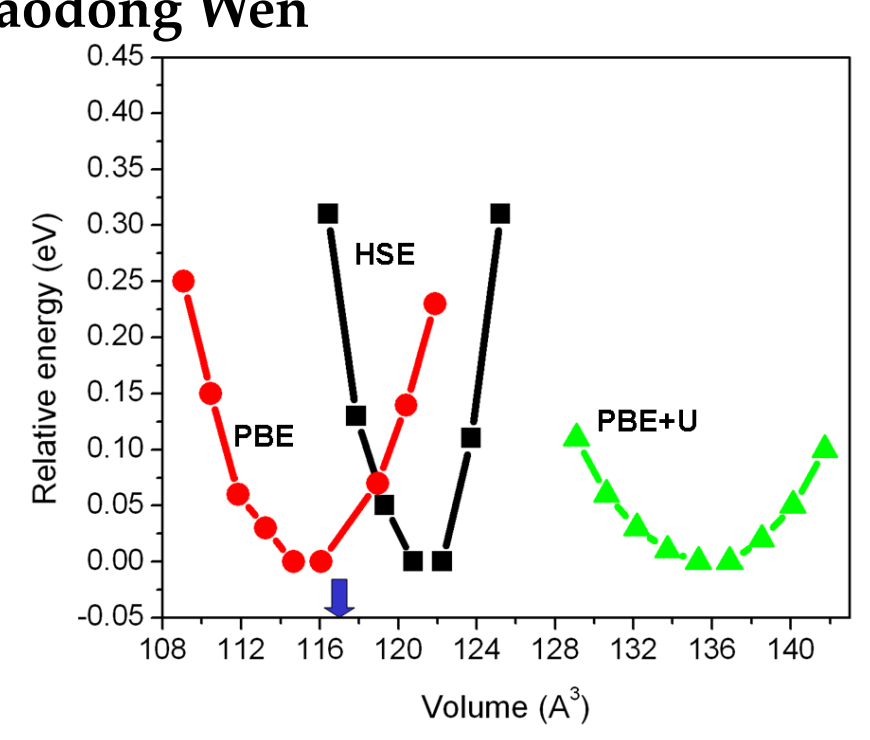

Energy as a function of volume using HSE, PBE and $P B E+U$ with experiment denoted by arrow.

Screened hybrid DFT is not so effective for the strongly correlated metals. Here we study UN with HSE, GGA, and $G G A+U$ approximations. HSE yields a much stiffer lattice and larger lattice constant. A comparison of the DOS as compared to angle resolved photoemission also shows that the hybrids are inferior to a simple GGA (PBE), and suggests that we must consider the dynamic screening of the Hartree-Fock exchange term if hybrids are to be effective for metals. 